\title{
Relationship between level of neutral buoyancy and dual-Doppler observed mass detrainment levels in deep convection
}

\author{
G. L. Mullendore ${ }^{1}$, A. J. Homann ${ }^{2}$, S. T. Jorgenson ${ }^{1}$, T. J. Lang ${ }^{3, *}$, and S. A. Tessendorf ${ }^{4}$ \\ ${ }^{1}$ Department of Atmospheric Sciences, University of North Dakota, Grand Forks, North Dakota, USA \\ ${ }^{2}$ National Weather Service, Indianapolis, Indiana, USA \\ ${ }^{3}$ Department of Atmospheric Science, Colorado State University, Fort Collins, Colorado, USA \\ ${ }^{4}$ Research Applications Laboratory, NCAR, Boulder, Colorado, USA \\ *now at: NASA Marshall Space Flight Center, Huntsville, Alabama, USA
}

Correspondence to: G. L. Mullendore (gretchen@atmos.und.edu)

Received: 12 July 2012 - Published in Atmos. Chem. Phys. Discuss.: 21 August 2012

Revised: 13 December 2012 - Accepted: 20 December 2012 - Published: 8 January 2013

\begin{abstract}
Although it is generally accepted that the level of neutral buoyancy (LNB) is only a coarse estimate of updraft depth, the LNB is still used to understand and predict storm structure in both observations and modeling. This study uses case studies to quantify the variability associated with using environmental soundings to predict detrainment levels. Nine dual-Doppler convective cases were used to determine the observed level of maximum detrainment (LMD) to compare with the LNB. The LNB for each case was calculated with a variety of methods and with a variety of sources (including both observed and simulated soundings). The most representative LNB was chosen as the proximity sounding from NARR using the most unstable parcel and including ice processes.

The observed cases were a mix of storm morphologies, including both supercell and multicell storms. As expected, the LMD was generally below the LNB, the mean offset for all cases being $2.2 \mathrm{~km}$. However, there was a marked difference between the supercell and non-supercell cases. The two supercell cases had LMDs of $0.3 \mathrm{~km}$ and $0.0 \mathrm{~km}$ below the LNB. The remaining cases had LMDs that ranged from $4.0 \mathrm{~km}$ below to $1.6 \mathrm{~km}$ below the LNB, with a mean offset of $2.8 \mathrm{~km}$ below. Observations also showed that evolution of the LMD over the lifetime of the storm can be significant (e.g., $>2 \mathrm{~km}$ altitude change in $30 \mathrm{~min}$ ), and this time evolution is lacking from models with coarse time steps, missing significant changes in detrainment levels that may strongly impact the amount of boundary layer mass transported to the upper troposphere and lower stratosphere.
\end{abstract}

\section{Introduction}

The most efficient method for transporting heat, moisture, and chemical tracers from the boundary layer to the upper troposphere and lower stratosphere is through moist convection (e.g., Dickerson, 1987; Pickering et al., 1988; Mullendore et al., 2005) . Deep convection allows constituents from the boundary layer to be transported within tens of minutes into the upper troposphere and lower stratosphere, where longer chemical residence times can increase their impact on the radiative budget, and higher wind speeds can increase their influence region from local to regional or even global (e.g., Dickerson, 1987; Pickering et al., 1993; Thompson et al., 1997).

For atmospheric chemistry models to correctly simulate the upper troposphere and lower stratosphere and their interactions, the level at which mass is being detrained from convection must be correctly simulated. These models must be initialized with accurate data and methodologies that provide reliable detrainment level estimations. In large-scale models where convection is not explicitly resolved, parameterizations of convective transport are utilized. These convective transport parameterizations use the level of neutral buoyancy (LNB), as calculated by parcel theory, as an upper bound of significant transport, assuming entrainment of environmental air will cause most parcels to be detrained below the LNB. Parcel theory struggles to accurately predict detrainment levels given the number of upper-air observations that are available and the lack of detail about storm morphology 
in the estimations. The purpose of this study is to attempt to quantify the variability associated with predicting detrainment levels.

In parcel theory, an initial parcel is chosen to best represent the environment being studied. The parcel is then lifted to obtain estimates of various environmental indices, such as convective available potential energy (CAPE) and LNB. The LNB (also known as equilibrium level, EL) is calculated from an environmental sounding by lifting a representative parcel of air from the surface to the level at which a parcel is no longer positively buoyant. Although simple to use, parcel theory can provide significantly varying estimations based on the choice of the initial parcel and the fact that the parcel chosen to be lifted is unlikely to be completely independent from the environment (Manzato and Morgan, 2003).

More specifically, using parcel theory to determine detrainment heights is highly idealized, and several of the problems inherent in the idealization are listed here. One, using a single column to represent the environment of a mesoscale system ignores the high spatial and temporal variability at cloud-scale, and choosing and/or measuring the "best" column is difficult. Two, parcel theory assumes that there is no entrainment of environmental air into the updraft, which one would expect to reduce buoyancy and, thus, detrainment heights. Approximating the amount of entrained air in a storm is important to accurately determine the level of detrainment, which is dependent on the thermodynamic profile, storm classification, and storm size (Cohen, 2000; Mullendore et al., 2005). Three, parcel theory neglects the dynamically induced vertical perturbation pressure gradients (e.g., Doswell and Markowski, 2004), producing an inaccurate picture of parcel accelerations and therefore inaccurate detrainment height estimates. Four, parcel theory assumes that a representative convective updraft can be defined with a single parcel, when in fact parcels entering the storm have a range of starting locations and properties. Existing convective parameterizations attempt to address some of the above challenges (e.g., parcel variability and entrainment estimates), but do not yet account for variability in updraft characteristics due to storm classification, such as possible updraft enhancements due to vertical pressure gradients in supercell storms (e.g., Arakawa, 2004; Randall et al., 2003).

In summary, to understand the potential for deep convective transport in certain storm regimes, we need to understand the relationship between the LNB and the observed level of maximum detrainment (LMD, Mullendore et al., 2009). This relationship was analyzed for tropical convection in a recent study by Takahashi and Luo (2012). They used CloudSat reflectivity data as a proxy for LMD ("LNB_maxMass" in their paper), and compared this to LNB values derived from ECMWF analysis profiles. They found that LMD is not wellcorrelated with LNB, as would be expected for reasons stated above. In addition, Takahashi and Luo (2012) found that the LMD was on average over $3 \mathrm{~km}$ lower than the LNB.
In this study, environmental soundings, from both observations and simulations, are analyzed and compared to one another to understand the near-storm environment before and during nine case studies and to estimate the LNB for various parcel theory assumptions. Vertical velocities derived from dual-Doppler analysis of each case study are then used to calculate the LMD in order to investigate the relationship between LNB and LMD. An overview of the field campaigns and associated observational platforms utilized in this study is presented in Sect. 2. Sections 3 and 4 describe the methodology and results for calculations of LNB and LMD, respectively. Section 5 summaries the LNB and LMD results, and conclusions are presented in Sect. 6 .

\section{Data}

Dual-Doppler radar data from nine midlatitude storms, representing several storm types, were utilized to calculate observed detrainment heights. Six cases were observed during the Severe Thunderstorm Electrification and Precipitation Study (STEPS, Lang et al., 2004). Three additional cases were observed as they passed through the dual-Doppler lobes of the Colorado State University (CSU) CHILL-Pawnee radar network. In addition, estimated idealized detrainment levels were calculated by utilizing both simulated and observed soundings (STEPS) or simulated soundings only (CHILL-Pawnee).

\subsection{Radar}

The STEPS campaign took place from 17 May to 20 July 2000 in eastern Colorado and western Kansas. Among the main observational platforms used in the campaign, three radars were used to create a triple-Doppler network (Fig. 1, panels b and e): the Colorado State University dual-polarization Doppler radar (CSU-CHILL) located near Burlington, Colorado, the NCAR S-band dualpolarization Doppler radar (S-Pol) located near Idalia, Colorado, and the National Weather Service (NWS) Weather Surveillance Radar-1988 Doppler (WSR-88D) at Goodland, Kansas (KGLD). The CHILL/Pawnee cases utilized CSUCHILL and a second S-band weather radar located at the CSU Pawnee site. Note that all the raw data quality control measures, interpolation, and dual-Doppler processing of radar data described herein was performed prior to this study; for more information on the processing done see Lang and Rutledge (2002, 2008); Tessendorf et al. (2005, 2007a,b); Wiens (2005). All altitudes for the CHILL/Pawnee cases were processed as above ground level (a.g.l.). The STEPS cases were converted to a.g.l. from mean sea level (m.s.l.) by subtracting the altitude of the KGLD radar $(1.1 \mathrm{~km})$. All cases had both reflectivity and velocities mapped to a regular Cartesian grid with $0.5 \mathrm{~km}$ resolution in the vertical, and 
Table 1. Summary of detrainment analysis for each case. Most representative level of neutral buoyancy (LNB) is calculated from the central NARR simulated sounding; mature level of maximum detrainment (LMD) is calculated by taking the mean LMD during the mature stage of the observed storm. The mean and standard deviation calculations for LNB include all non-zero methods from all collected soundings (e.g. see Table 2 for LNB calculations for STEPS 6/29 case). All STEPS cases are from 2000; all CHILL cases are from 1998. All altitudes are given as a.g.1.

\begin{tabular}{cccccc}
\hline Case & Storm Type & $\begin{array}{c}\text { Most Representative } \\
\text { LNB }(\mathrm{km})\end{array}$ & $\begin{array}{c}\text { Mean LNB } \\
(\mathrm{km})\end{array}$ & $\begin{array}{c}\text { LNB Standard } \\
\text { Deviation }(\mathrm{km})\end{array}$ & $\begin{array}{c}\text { Mean LMD } \\
(\mathrm{km})\end{array}$ \\
\hline STEPS 6/3 & single cell & 11 & 10.1 & 0.8 & 8.2 \\
STEPS 6/11 & convective line & 11.4 & 10.4 & 1 & 8.3 \\
STEPS 6/19 & convective line & 10.7 & 10.4 & 1.4 & 6.7 \\
STEPS 6/22 & convective line & 12.3 & 12 & 0.6 & 10.5 \\
STEPS 6/23 & multicell & 12.7 & 11.3 & 1.3 & 8.8 \\
STEPS 6/29 & supercell & 12.3 & 11.4 & 1 & 12.3 \\
CHILL 7/2 & supercell & 11.1 & 10.7 & 0.3 & 10.8 \\
CHILL 7/15 & convective line & 11.9 & 10.7 & 1.3 & 9.4 \\
CHILL 7/21 & multicell & 12.6 & 12.2 & 0.2 & 10.9 \\
\hline
\end{tabular}

either 0.5 or $1.0 \mathrm{~km}$ resolution in the horizontal (see dualDoppler processing articles cited above).

\subsection{Mobile soundings}

NCAR mobile soundings systems (M-GLASS) were deployed during STEPS to characterize the storm environment (Lang et al., 2004). The times (UTC) and locations of the mobile soundings collected for the 29 June 2000 and 22 June 2000 cases are shown in Fig. 1, panels b and e, as triangles. Some soundings from the campaign were not used due to missing upper-level data (e.g., the 29 June 20:00, 23:55 UTC sounding recorded no data above $300 \mathrm{hPa}$ ). Bad data points, e.g., anomalous spike in the 29 June 2000, 20:22 UTC sounding, and superadiabatic layers near the surface in some mobile soundings, were removed from the sounding data before calculating parcel ascents. Mobile sounding altitudes are given as a.g.l.

\subsection{NARR soundings}

As previously discussed, traditional environmental soundings are limited in time and space and therefore do not always provide reliable information about pre-storm environments. One source of information that is useful for supplementing environmental soundings after a storm has occurred is the North American Regional Reanalysis (NARR) dataset (Mesinger et al., 2006). The reanalysis data have a horizontal grid spacing of 32-km, 29 layers in the vertical, and 3-hourly output. To obtain a sounding representative of the pre-storm environment using NARR data, the "proximity sounding" methodology was used (Thompson et al., 2003), i.e. a location was chosen $30 \mathrm{~min}$ or $40 \mathrm{~km}$ upwind and in the path of the storm. For this study, a point was chosen along the eastern or southern edge of the reflectivity region, depending on storm propagation direction, of a given storm at 00:00 UTC (except for the 21 July 1998 CHILL case, which used the time 21:00 UTC). The NARR grid point closest to this location was calculated, and then the proximity NARR sounding was chosen as the location one or two points further east or south (resulting in a distance from storm of 33 to $63 \mathrm{~km}$ ). This proximity sounding was also labeled as "most representative", and additional simulated soundings were read from the grid points surrounding the most representative location (Fig. 1, plus signs; "most representative" location is bolded), to sample the local variability. All NARR soundings were converted to a.g.l. by subtracting out the surface altitude of the chosen grid point and interpolated to $250 \mathrm{~m}$ vertical grid spacing using cubic interpolation. Throughout the remainder of this article, all altitudes are given as a.g.l.

\subsection{Case overview}

Table 1 lists the nine cases that were used for this study. The cases studied included single cell and multicell storms, supercells, and convective lines. Figure 1 presents an overview of the 29 June 2000 STEPS supercell case (panels a-c) and the 22 June STEPS convective line case (panels $d-f$ ). Panels $a$ and $d$ show a visible satellite image of each case, with the dual-Doppler analysis area highlighted with a yellow square. Panels $\mathrm{b}$ and e show horizontal cross-sections of radar reflectivity at $2 \mathrm{~km}$ height (a.g.l), and indicate the location of the vertical cross-section, shown in panels $\mathrm{c}$ and $\mathrm{f}$. More detailed information on the STEPS cases can be found in the mission summaries from the STEPS campaign archive (UCAR, 2012a). In addition, many of these cases have been described in detail in previous studies (Lang and Rutledge, 2002; Lang et al., 2004; Tessendorf et al., 2005; Kuhlman et al., 2006; Lang and Rutledge, 2008). Classification of these storms was based on all sources cited herein; the "convective line" designation was chosen to be general, describing a system with significant areas of both convective and stratiform structures, with the convective elements being at least quasi-linear. Note 

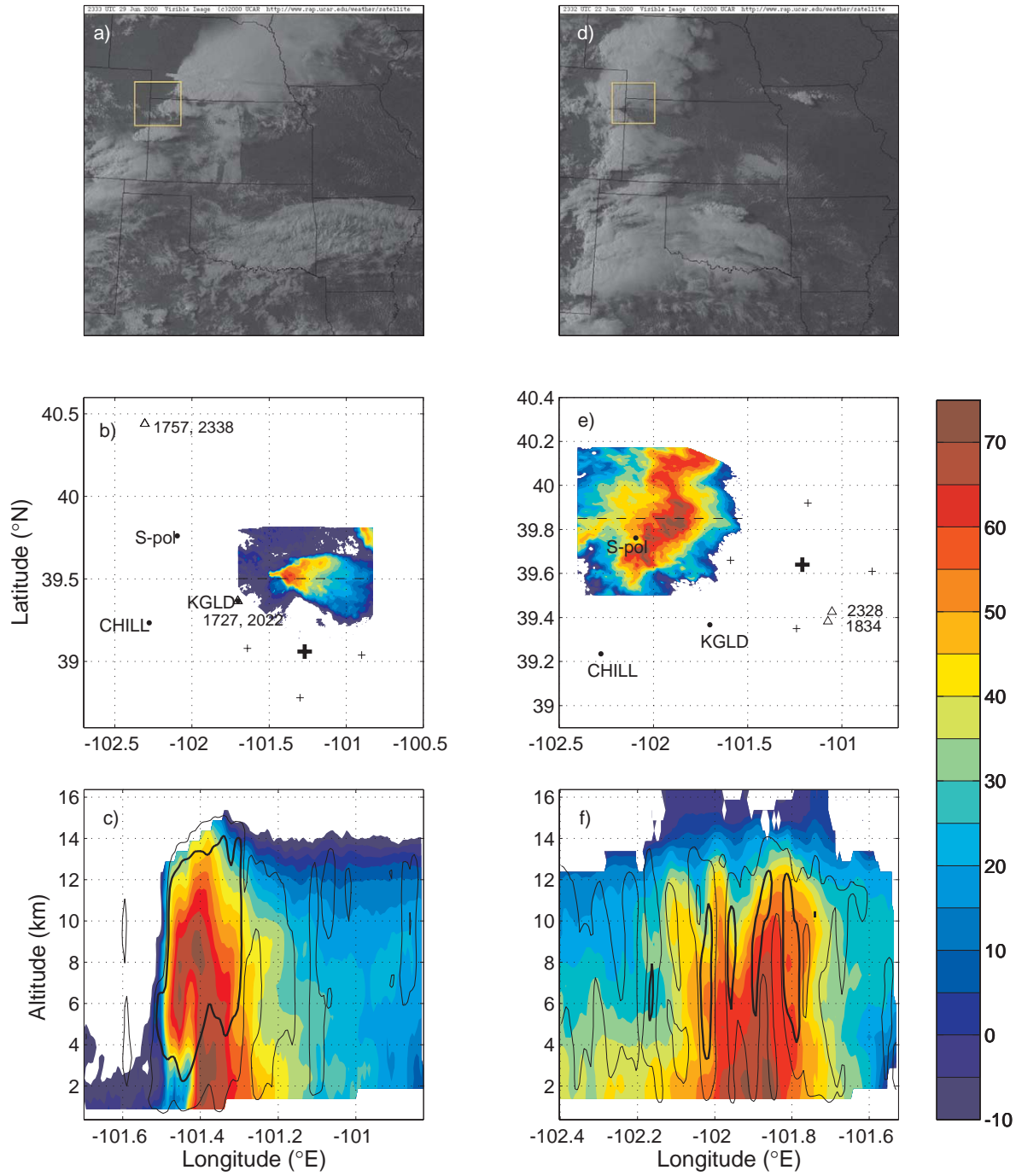

Fig. 1. Overview of the 29 June 2000 STEPS supercell case at time 23:57 UTC (a-c) and the 22 June STEPS convective line case at time 00:48 UTC (d-f). Panels a and d show a visible satellite image of each case, with the dual-Doppler analysis area highlighted with a yellow square. Panels b and e show horizontal cross-sections of radar reflectivity (dBZ) at $2 \mathrm{~km}$ height (a.g.l). Solid dots indicate radar locations, triangles indicate locations of mobile soundings (with launch times labeled), and plus marks show locations of NARR simulated soundings. The bolded plus mark indicates the "most representative" NARR sounding. (c) and (f) show vertical cross-sections of radar reflectivity (dBZ)

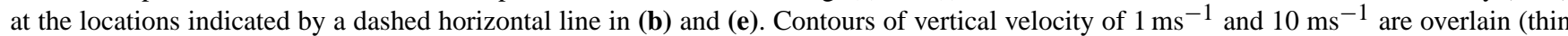
and thick black lines, respectively).

that while the 11 June 2000 convective line case did not have an observed embedded supercell, a relatively large and persistent single cell was observed at the southern end of the line.

\section{LNB calculations}

It is generally accepted that level of neutral buoyancy (LNB) derived from environmental profiles is highly variable, and sensitive to several parameters including choice of initial parcel and method of calculation (e.g., irreversible or reversible ascent). With the goal of quantifying the variability, several calculations were performed for each observed and simulated sounding. Three different initial parcels were used in each case - the surface-based parcel (surface air and dewpoint temperatures), the most unstable parcel (air and dewpoint temperatures at the height where the equivalent potential temperature, $\Theta_{e}$, was the greatest in the lowest $500 \mathrm{hPa}$ ), and the mixed-layer parcel (average of the lowest $1500 \mathrm{~m}$ ). Calculations were performed using all three initial parcels assuming both liquid water processes only and also incorporating both liquid and ice processes. Ice processes were included following the work of Bryan and Fritsch (2004), which allows for mixed phase processes between 0 and $-40{ }^{\circ} \mathrm{C}$. Note that 
Table 2. Level of neutral buoyancy (LNB) calculated for the STEPS 6/29 case, including simulated (NARR) and observed soundings. LNB is calculated assuming irreversible (pseudoadiabatic) ascent using two methods (liquid only hydrometeors and liquid and frozen hydrometeors) and using three different initial parcel assumptions (surface-based, mixed layer, and most unstable).

\begin{tabular}{|c|c|c|c|c|c|c|c|}
\hline \multicolumn{2}{|l|}{ STEPS $6 / 29$} & \multicolumn{3}{|c|}{ Liquid Only LNB (km) } & \multicolumn{3}{|c|}{ With Ice LNB (km) } \\
\hline Location & Time (UTC) & Surface & $\begin{array}{l}\text { Mixed } \\
\text { Layer }\end{array}$ & $\begin{array}{c}\text { Most } \\
\text { Unstable }\end{array}$ & Surface & $\begin{array}{l}\text { Mixed } \\
\text { Layer }\end{array}$ & $\begin{array}{c}\text { Most } \\
\text { Unstable }\end{array}$ \\
\hline NARR $38.78^{\circ} \mathrm{N}, 101.30^{\circ} \mathrm{W}$ & 30/06 00:00 & 12 & 11.8 & 12 & 12.3 & 12 & 12.3 \\
\hline NARR South & 30/06 00:00 & 12.1 & 11.8 & 12.1 & 12.3 & 12.1 & 12.3 \\
\hline NARR West & 30/06 00:00 & 11.6 & 11.4 & 11.6 & 11.6 & 11.6 & 11.9 \\
\hline NARR East & 30/06 00:00 & 12.1 & 11.8 & 12.1 & 12.1 & 12.1 & 12.1 \\
\hline $39.367^{\circ} \mathrm{N}, 101.703^{\circ} \mathrm{W}$ & 29/06 17:27 & NA & NA & 8.9 & NA & NA & NA \\
\hline $40.441^{\circ} \mathrm{N}, 102.306^{\circ} \mathrm{W}$ & 29/06 17:57 & 10.8 & 9.4 & 11 & 10.6 & 9.3 & 10.9 \\
\hline $39.367^{\circ} \mathrm{N}, 101.703^{\circ} \mathrm{W}$ & 29/06 20:22 & 10.9 & 10.8 & 11.1 & 10.7 & 10.6 & 10.9 \\
\hline $40.441^{\circ} \mathrm{N}, 102.306^{\circ} \mathrm{W}$ & 29/06 23:38 & NA & NA & 8.5 & NA & NA & NA \\
\hline
\end{tabular}

calculations were also done assuming all condensed water fell out of the parcel (irreversible, or pseudoadiabatic ascent) and again under the assumption that no condensed water fell out of the parcel (reversible ascent). However, the results incorporating reversible ascent were not significantly different from the irreversible calculations. Therefore, only the irreversible results are shown throughout the remainder of this study.

Table 2 shows the calculated LNB for multiple methodologies for the 29 June 2000 STEPS case. Parcels with no buoyancy, or insignificant buoyancy (LNB $<5 \mathrm{~km}$ ), were labeled as "NA" in the table, and were not used in calculation of LNB statistics (Table 1). For parcels with significant buoyancy, LNB ranged from 8.5 to $12.3 \mathrm{~km}$, showing significant variability due to methodology and data sources. Focusing on differences due to methodology alone, choice of surface parcel caused differences up to $1.7 \mathrm{~km}$ for calculated LNB (Table 2, 17:57 UTC), and often was the difference between a buoyant ascent and no buoyancy at all (e.g., 17:27 UTC). For a given initial parcel type, inclusion of ice processes had a relatively small impact on the calculated LNB $(<0.5 \mathrm{~km})$. However, inclusion of ice is more physically accurate, so should be included in the absence of computational constraints. The differences between LNB estimations obtained using just one sounding emphasize the amount of variability in estimating the LNB from environmental soundings.

Variability in LNB is also seen due to spatial and temporal variability. As seen in results for a single methodology (Table 2; most unstable parcel with ice), calculated LNB ranges from 10.9 to $12.3 \mathrm{~km}$, representing soundings taken over a $6.5 \mathrm{~h}$ time period and covering a distance of $236 \mathrm{~km}$. Based on time and position, the most representative of the mobile soundings is the 20:22 UTC sounding (the 23:38 UTC sounding was likely contaminated by convection occurring to the north of the main storm). Comparing the most representative mobile sounding to the most representative NARR sounding shows that the LNB calculated from NARR is over $1 \mathrm{~km}$ higher than the LNB calculated from the mobile sounding.
This positive bias in the NARR soundings was seen in all the STEPS cases, with the offset between the most representative NARR sounding and the average mobile soundings ranging from $0.2 \mathrm{~km}$ (STEPS 6/19) to $2.1 \mathrm{~km}$ (STEPS 6/11, 6/23).

Table 1 shows the variability in LNB for all cases analyzed. Individual LNB values using all calculation methods for all cases (not shown) demonstrates that for all but one of the cases, LNB values calculated using the surface-based parcel and the most-unstable parcel are within $0.5 \mathrm{~km}$. This is similar to the finding in Takahashi and Luo (2012) that, for tropical convection cases, LNB values calculated by using the surface parcel and the parcel with maximum moist static energy were nearly identical. However, for one case, the 15 July CHILL storm, the LNB values using the surface-based parcels were $3.0 \mathrm{~km}$ lower than LNB values using the mostunstable parcels, suggesting an elevated convective regime. Therefore, the most representative LNB (Table 1, column 3) is chosen to be the most unstable parcel calculated with ice processes from the central NARR sounding. Columns 4 and 5 show the mean value and standard deviation for a particular case using all data methodologies and all soundings. As is expected, the mean LNB is lower in all cases than the most representative, as the most unstable parcel with ice processes is most likely to produce the highest LNB values. The variability seen in the 29 June 2000 case is typical for all cases, as seen in the standard deviation values.

In summary, determining a single LNB value for a given storm is difficult, as the LNB is highly variable, dependent on the choice of lifted parcel, method of calculation, source of sounding (observed versus simulated), local spatial and temporal variability, and storm-relative location. In any storm, the likelihood of having a single representative sounding valid for the lifecycle of the entire storm is low. However, this case study is a "best case scenario", as the temporal and spatial resolution is significantly greater in a field campaign with special soundings than cases that rely only on regular weather station soundings. Although the LNB is widely recognized as only an approximation to the actual level at which 
parcels will detrain from the updraft, it remains an important index for understanding convective dynamics and predicting the depths of convective mixing. Therefore, systematic testing of the relationship between LNB and observed storm detrainment height is important.

\section{LMD calculations}

To compare with LNB calculations, an estimate of the actual detrainment heights is needed. Aircraft chemical retrievals are not available for the cases presented, and even when available, in situ measurements present the challenge of being only point measurements of the complex threedimensional, time-variable storm. Chemical concentrations from satellite retrievals are not able to resolve both the horizontal and vertical cloud-scale transports (i.e. horizontal scales of order $1 \mathrm{~km}$ and vertical scales of order $100 \mathrm{~m}$ ). Vertical velocities derived from dual-Doppler radar retrievals can be used to estimate the level at which mass was detrained in the observed storm (Mullendore et al., 2009). At the level where the vertical momentum decelerates most sharply, parcels will accumulate due to a maximum in vertical convergence. Assuming local changes in density are negligible relative to the mass flux, this means that the same amount of mass must be exiting the volume horizontally. Therefore, the level at which a maximum in vertical convergence occurs is expected to be the same level at which horizontal divergence is maximized. Throughout this study, the level of maximum horizontal divergence will be considered to be synonymous with the level of maximum detrainment (LMD), i.e. the location at which the transfer of air from an updraft is maximized.

The vertical divergence profile ( $\partial \rho w / \partial z$, Fig. 2) was calculated for each vertical column and then horizontally integrated over the entire dual-Doppler domain at each time. Vertical divergence was calculated by taking a first order forward difference along each vertical column. This calculation included an estimate of the variability of density $(\rho)$ with height by incorporating the basic equation

$\rho=\rho_{0} \exp (z / H)$,

where $\rho_{0}$ is $1.22 \mathrm{~kg} \mathrm{~m}^{-3}, H$ is $7 \mathrm{~km}$, and $z$ is the altitude $(\mathrm{km})$ of the calculation, as was used in the dual-Doppler calculations. These vertical divergence values were then horizontally-integrated to derive a net vertical divergence value at each height. Note that the horizontally-integrated vertical divergence values were calculated by including positive vertical velocities only. Negative velocities were removed because the main goal is to diagnosis the level of detrainment for deep transport from the boundary layer, and, as shown in Fig. 4c of Mullendore et al. (2009), vertical divergence in deep downdrafts can alter the signature of vertical convergence due to the deep updrafts alone.

Figure 2 shows the calculated horizontal detrainment for the 29 June 2000 supercell case at 23:57 UTC (dashed line).

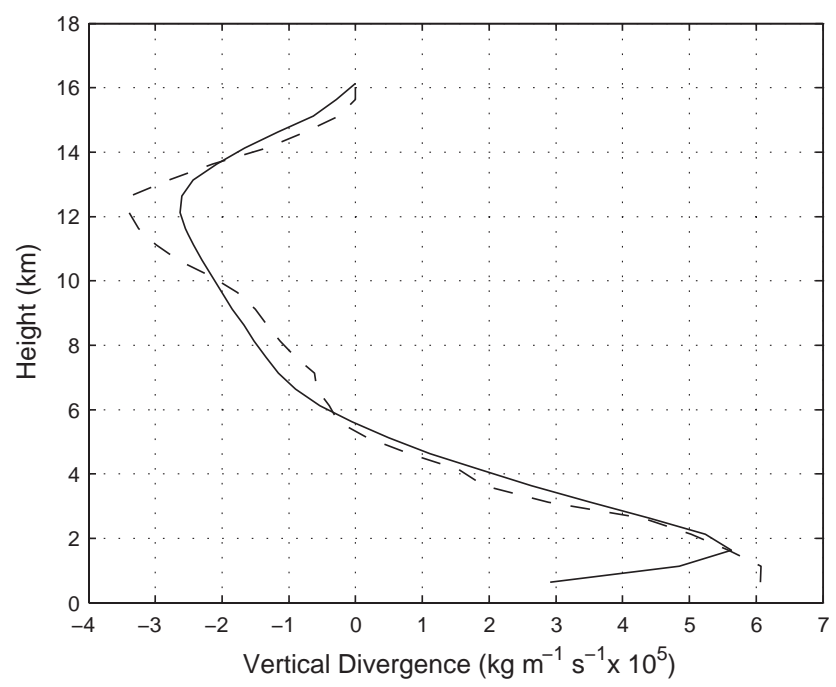

Fig. 2. Horizontally-integrated vertical divergence for the 29 June 2000 supercell case at 23:57 UTC (dashed line) and averaged over all times (solid line). The level of maximum detrainment (LMD) is $12.1 \mathrm{~km}$ for the $23: 57$ UTC divergence line, and $12.3 \mathrm{~km}$ for the time-averaged divergence line.

From this graph, we can define the LMD, $12.1 \mathrm{~km}$, and the "detrainment envelopment", or the range of values over which vertical divergence is negative, suggesting horizontal detrainment. For the time shown, the detrainment envelopment extends from 5.3 to $15.6 \mathrm{~km}$. By averaging over all sampled times, we can obtain an average detrainment envelope for the storm (Fig. 2; solid line). The time-averaged LMD for this case is $12.3 \mathrm{~km}$.

To investigate how the deep convective detrainment evolved with time, the detrainment envelope was plotted at each observation time and the altitudes of the LMD (Fig. 3; red line), and minimum (gray line) and maximum (blue line) extent, were recorded. The black dashed line shows the most representative LNB. As stated previously, the LNB is generally considered an upper bound on the LMD, but from observation times 23:57 UTC onward, the LMD is approximately at or above the most representative LNB. The magnitude of the LMD was also recorded at all times; the case-normalized LMD magnitude is shown on the right-hand y-axis of Fig. 3 (solid black line). The 29 June 2000 case was unique in that it showed a significant increase in the altitude (Fig. 3; red line) of the LMD over time, with a mean altitude of $11.0 \mathrm{~km}$ before the strengthening period (23:20 to 23:38 UTC; solid black line) and a mean altitude of $12.3 \mathrm{~km}$ after the strengthening period. This increase in LMD strength and altitude corresponds to the time of the strong right turn ("severe right mature phase"; Tessendorf et al., 2005). The timing of this increase suggests that the enhancement in transport corresponds to the co-location of the supercell updraft with positive vertical pressure gradient forcing to the south of the original updraft (e.g., Rotunno and Klemp, 1985). However, 


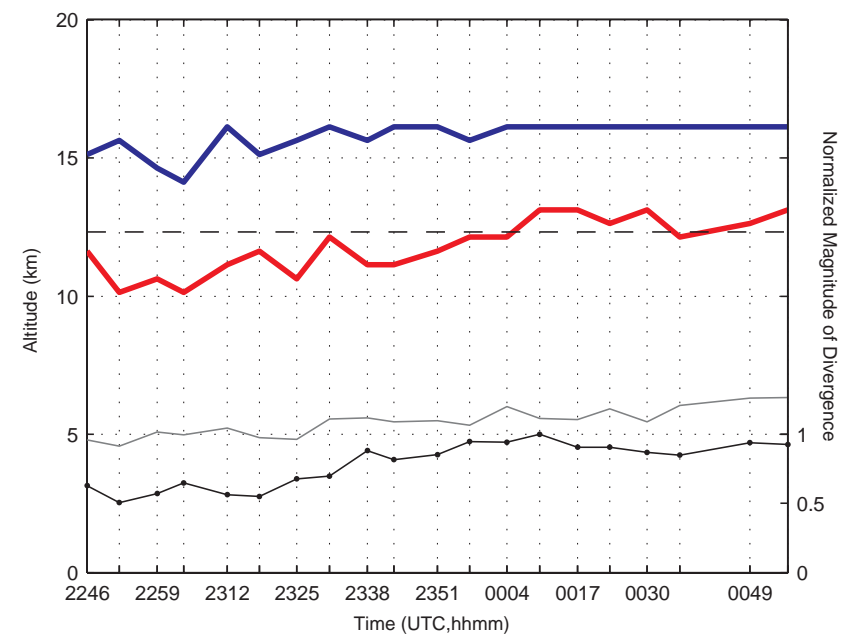

Fig. 3. Left axis: Time evolution of detrainment in 29 June 2000 supercell case including level of maximum detrainment (LMD; red line) and maximum (blue line) and minimum (gray line) extent of detrainment envelope. The altitude of the LNB from the most representative sounding is shown as a black dashed line. Right axis: Time evolution of normalized detrainment magnitude (black line) for same case.

investigation into the maximum updraft strength and updraft depth does not show a simply understood relationship, and this case is further complicated by upper-level temperature structure with multiple stability layers. This case is currently being investigated in a modeling environment to better understand the causes of significant amounts of detrainment above the LNB, and highlights the importance of storm morphology in understanding deep convective transport.

Most of the cases analyzed fit what was expected, i.e. the mean LMD was below the most representative LNB. Figure 4 shows the time evolution of detrainment envelope, identical to what is shown in Fig. 3 for the 29 June 2000 case, for the additional eight cases (the 3 June and 11 June 2000 STEPS cases, panels $\mathrm{d}$ and $\mathrm{e}$, have gaps in the returns due to radar scanning strategies that limited dual-Doppler coverage during those times). The 2 July 1998 CHILL supercell case (panel a) had LMDs (red line) near the altitude of the most representative LNB (black dashed line). The 11 June 2000 STEPS convective line (panel e) had two observed times where the LMD was near the LNB, features which may result from a markedly large cell embedded in the line. Figure 4 also demonstrates that all the cases studied had significant variability in time, in either the LMD, the depth of the detrainment envelope, or the magnitude of detrainment (shown as normalized detrainment magnitude in Fig. 4; black line). The time variability of detrainment is not captured in a signal snapshot, highlighting an additional challenge in estimating detrainment values from a single environmental sounding.

In addition, even when the LMD was below the most representative LNB, the maximum extent of the detrainment en- velope (blue lines) was at most times above the LNB, suggesting some transport occurred above the LNB, and in certain cases, extended up to $16 \mathrm{~km}$. This depth suggests that at least in some cases the storms were transporting boundary layer mass directly into the lowermost stratosphere. For a given storm, irreversible transport associated with the region of the detrainment envelope from the LMD to its upper edge is due to turbulence in both the overshooting tops and also along the upper edge of the anvil cloud. As discussed in Mullendore et al. (2005), the majority of the air in overshooting tops is negatively buoyant, and therefore descends back to lower altitudes. However, due to vigorous mixing at the top of the storm (e.g., Fig. 9 of Mullendore et al., 2005; Lane et al., 2003), a portion of the overshooting air is mixed with stratospheric air, thereby attaining neutral buoyancy and irreversible transport. Although the percentage of the air irreversibly transported via overshooting tops (and, more generally, via mixing at cloud top) is small compared to the amount of transport occurring at the LMD, this amount can be very important because of transport of even small concentrations of reactive chemicals into the lowermost stratosphere. Additional analysis of the amount transported to the stratosphere requires careful treatment of the tropopause, as the tropopause region becomes poorly defined above active convection (e.g., Mullendore et al., 2005), therefore further quantification of the cross-tropopause transport is beyond the scope of the current analysis.

It should be noted the detrainment envelope calculations are sensitive to dual-Doppler processing, e.g., the case presented in Mullendore et al. (2009) from the LBA-TRMM campaign had spurious near-surface velocities away from main updrafts, which contaminated an analysis of the full domain and forced a more subjective selection of analysis areas. Even in the cases presented here, some lower level contamination existed; for times where significant lower level uncertainty existed, no lower bound on the detrainment envelope (Fig. 4a, b; dashed gray lines) was recorded. An objective methodology for choosing the analysis region, with focus on the anvil region of a given case, is currently being tested (e.g., Feng et al., 2011).

\section{Relationship between LNB and LMD}

The mean LMD calculated for each case is given in Table 1 . The mean LMD was calculated by averaging the LMD values over all times observed, except in the case of the 29 June 2000 STEPS supercell. For the 29 June 2000 case, two LMDs were calculated, one before strengthening (to 23:20 UTC, $10.9 \mathrm{~km}$ ) and one after strengthening (from 23:38 UTC, $12.3 \mathrm{~km}$ ); the post-strengthening LMD is used in comparison figures. As follows from the discussion of the time-varying LMD in Sect. 4, the mean LMD was below the LNB in all cases except for the 29 June 2000 STEPS case, which had a mean LMD equal to the LNB. Figure 5 

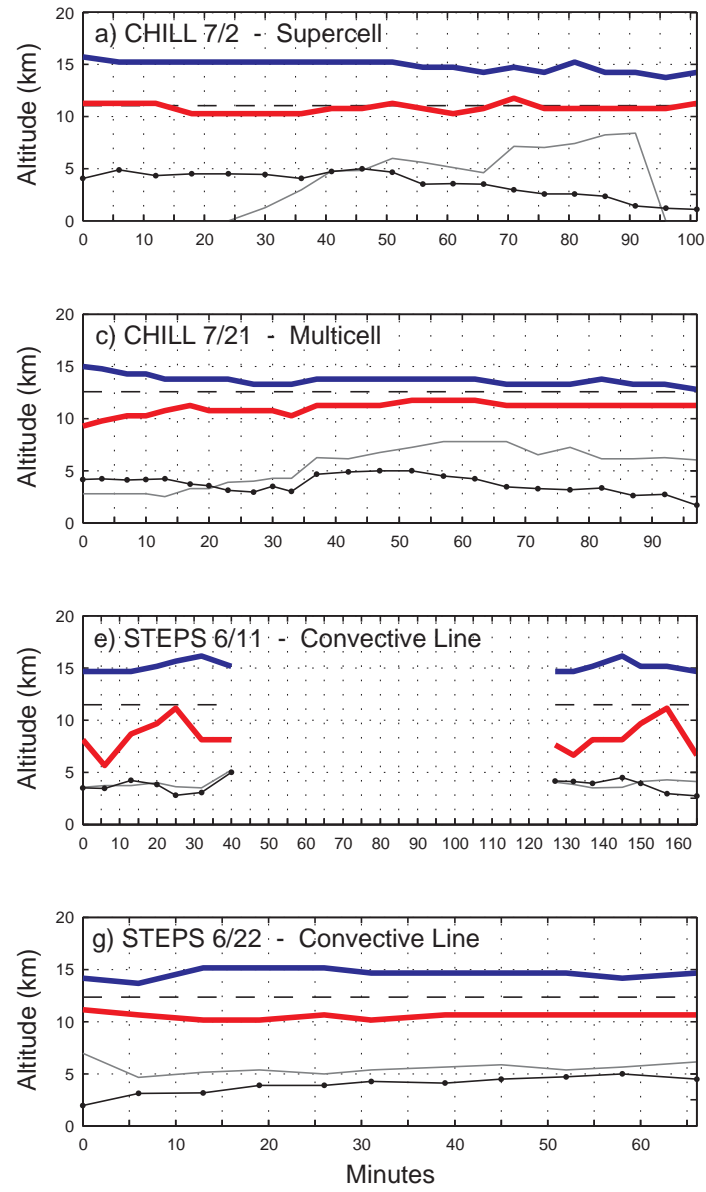

Fig. 4. Same as shown in Fig. 3, but for additional case studies.

summarizes the comparison between the most representative LNB (x-axis) and mean LMD (y-axis). The one-to-one comparison is plotted as a gray solid line. The supercell cases (shown as diamonds) had markedly higher LMDs than the other storm types ( $\mathrm{x}$ is single cell, plus signs are multicells, circles are convective lines). On average, all other storms had mean LMD values $2.8 \mathrm{~km}$ below the most representative LNB (Fig. 5, gray dashed line). This offset for nonsupercell storms is similar to the average offset found for a large data set of tropical convection over land (offset between LNB_maxMass and LNB of $3.1 \mathrm{~km}$; Takahashi and Luo, 2012).

The offset between extent of the detrainment envelope and LNB was also investigated, with the average offset calculated for each storm individually, then averaged over all storms. The average maximum extent of the detrainment envelope ranged from $3.7 \mathrm{~km}$ above the LNB to $0.9 \mathrm{~km}$ below, with an average offset of $1.6 \mathrm{~km}$ above. The average minimum extent of the detrainment envelope ranged from $4.2 \mathrm{~km}$ to $7.5 \mathrm{~km}$ below the LNB, with an average offset of $6.7 \mathrm{~km}$ below. The detrainment envelope extent corresponds to detrainment levels as shown in Takahashi and Luo (2012), specifically
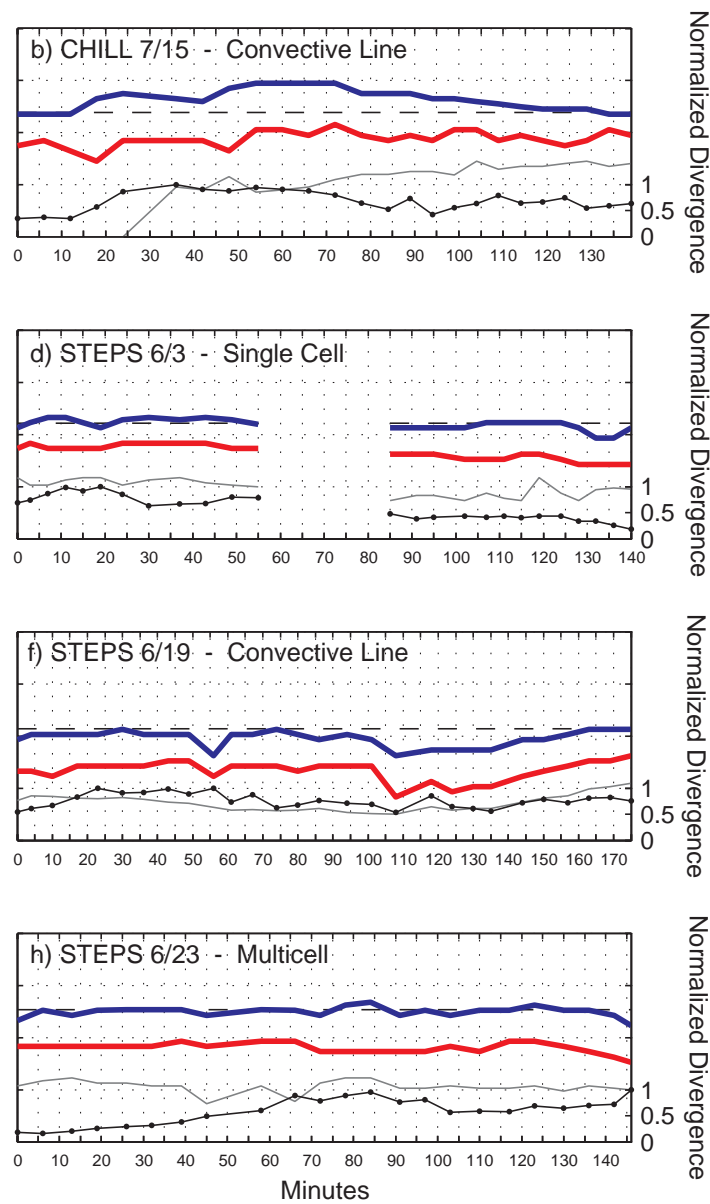

LNB_CTH (maximum extent) and LNB_CBH (minimum extent). The mean offsets for maximum and minimum extent in that study (for tropical convection over land) are $0.4 \mathrm{~km}$ below the LNB and $5.3 \mathrm{~km}$ below the LNB, respectively, which is a smaller average detrainment envelope depth than found for the nine midlatitude cases. This difference may be partially due to the fact that Takahashi and Luo (2012) uses radar reflectivity as a proxy for deep convective transport, and the study presented here only uses dual-Doppler derived divergence profiles. However, Mullendore et al. (2009) also uses reflectivity as proxy, and found good agreement between the two methods. Additional research is currently being conducted to more fully understand the relationship between divergence profiles and reflectivity.

\section{Conclusions}

As stated in Sect. 1, the purpose of this study is to quantify the variability associated with predicting detrainment levels, specifically the prediction from environmental soundings. Although it is generally accepted that the level of neutral 


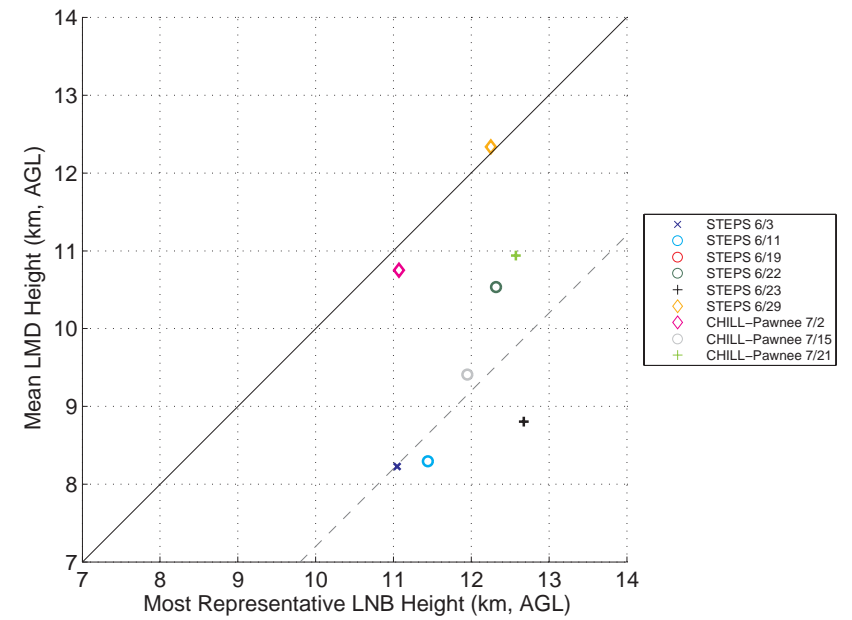

Fig. 5. Most representative LNB height $(\mathrm{km})$ plotted versus mean LMD height ( $\mathrm{km}$, see text for details). Each case is designated by different color, and the shapes designate storm type: $\mathrm{x}$ for single cell, plus sign for multicell, circle for convective line, and diamond for supercell. The LNB versus LMD one-to-one line is plotted for reference as a solid gray line; a line representing LNB $2.8 \mathrm{~km}$ above the LMD is plotted as dashed gray.

buoyancy (LNB) is only a coarse estimate of updraft depth (as detailed in Sect. 3), the LNB is still used to understand and predict storm structure. Using a method proposed in Mullendore et al. (2009), nine dual-Doppler convective cases were used to determine the observed level of maximum detrainment (LMD) to compare with the LNB. The LNB for each case was calculated with a variety of methods and with a variety of sources (including both observed and simulated soundings). The most representative LNB was chosen as the proximity sounding from NARR using the most unstable parcel and including ice processes.

The observed cases were a mix of storm morphologies, including both supercell and multicell storms. As expected, the LMD was generally below the LNB, the mean offset for all cases being $2.2 \mathrm{~km}$. However, there was a marked difference between the supercell and non-supercell cases. The two supercell cases had LMDs just below $(0.3 \mathrm{~km} ; 2$ July 1998) or equal to (29 June 2000) the LNB. The mean offset for all other cases was a LMD $2.8 \mathrm{~km}$ below the LNB. These findings are significant for two reasons. First, the LNB is considered an upper bound on significant convective mass transport, as calculations of LNB ignore parcel mixing, which would be expected to reduce updraft depth. The findings presented here suggest that, for time-averaged values, using LNB as an upper bound may be appropriate, but only with careful selection of environmental sounding. Additionally, the assumption often made that the LMD is below the LNB does not always hold true, and at certain observed times, the LMD is even above the LNB. Second, storm morphology has a significant impact on mass transport (e.g., Mullendore et al., 2005), suggesting that internal storm dynamics are important for transport calculations. However, with further case studies, a predictable relationship between LNB and LMD may yet be determined for a given storm regime. The Deep Convective Clouds and Chemistry (UCAR, 2012b) field campaign will provide several additional cases that can provide further insights into the relationships presented in this study.

This study has also demonstrated the evolution of the LMD over the lifetime of the storm can be significant (e.g., $>2 \mathrm{~km}$ altitude change in $30 \mathrm{~min}$ for 29 June 2000 supercell), and this time evolution is lacking from models with coarse time steps, missing significant changes in detrainment levels that may strongly impact the amount of boundary layer mass transported to the lower stratosphere.

Acknowledgements. This work was supported by the National Science Foundation Division of Atmospheric Sciences, NSF grant ATM-0918010. The authors would like to thank George Bryan for making available his parcel ascent code to calculate CAPE, Aaron Kennedy for assistance in obtaining the NARR data, and Kurtis Pinkney for assistance with data analysis. The authors thank Jeffrey Tilley, Matt Gilmore, and Mark Askelson for helpful comments and discussions. The authors also thank Zhengzhao Johnny Luo and the anonymous reviewer for their valuable feedback.

Edited by: T. Garrett

\section{References}

Arakawa, A.: The cumulus parameterization problem: Past, present, and future, J. Climate, 17, 2493-2525, 2004.

Bryan, G. H. and Fritsch, J. M.: A Reevaluation of Ice-Liquid Water Potential Temperature, Mon. Weather Rev., 132, 2421-2431, doi:10.1175/1520-0493(2004)132<2421:AROIWP>2.0.CO;2, 2004.

Cohen, C.: A quantitative investigation of entrainment and detrainment in numerically simulated cumulonimbus clouds, J. Atmos. Sci., 57, 1657-1674, 2000.

Dickerson, R. R.: Thunderstorms: An important mechanism in the transport of air pollutants, Science, 235, 460-465, 1987.

Doswell III, C. A. and Markowski, P. M.: Is Buoyancy a Relative Quantity?, Mon. Weather Rev., 132, 853-863, 2004.

Feng, Z., Dong, X., Xi, B., Schumacher, C., Minnis, P., and Khaiyer, M.: Top-of-atmosphere radiation budget of convective core/stratiform rain and anvil clouds from deep convective systems, J. Geophys. Res. D Atmos., 116, 2011.

Kuhlman, K. M., Ziegler, C. L., Mansell, E. R., MacGorman, D. R., and Straka, J. M.: Numerically simulated electrification and lightning of the 29 June 2000 STEPS supercell storm, Mon. Weather Rev., 134, 2734-2757, 2006.

Lane, T. P., Sharman, R. D., Clark, T. L., and Hsu, H.-M.: An investigation of turbulence generation mechanisms above deep convection, J. Atmos. Sci., 60, 1297-1321, 2003.

Lang, T. J. and Rutledge, S. A.: Relationships between convective storm kinematics, precipitation, and lightning, Mon. Weather Rev., 130, 2492-2506, 2002.

Lang, T. J. and Rutledge, S. A.: Kinematic, microphysical, and electrical aspects of an asymmetric bow-echo mesoscale convective 
system observed during STEPS 2000, J. Geophys. Res. D: Atmos., 113, D08213, doi:10.1029/2006JD007709, 2008.

Lang, T. J., Miller, L. J., Weisman, M., Rutledge, S. A., Barker, III, L. J., Bringi, V. N., Chandrasekar, V., Detwiler, A., Doesken, N., Helsdon, J., Knight, C., Krehibiel, P., Lyons, W. A., MacGorman, D., Rasmussen, E., Rison, W., Rust, W. D., and Thomas, R. J.: The Severe Thunderstorm Electrification and Precipitation Study, B. Am. Meteor. Soc., 1107-1125, 2004.

Manzato, A. and Morgan, G.: Evaluating the sounding instability with the Lifted Parcel Theory, Atmos. Res., 67-68, 455-473, 2003.

Mesinger, F., DiMego, G., Kalnay, E., Mitchell, K., Shafran, P. C., Ebisuzaki, W., Jović, D., Woollen, J., Rogers, E., Berbery, E. H., Ek, M. B., Fan, Y., Grumbine, R., Higgins, W., Li, H., Lin, Y., Manikin, G., Parrish, D., and Shi, W.: North American regional reanalysis, B. Am. Meteorol. Soc., 87, 343-360, 2006.

Mullendore, G. L., Durran, D. R., and Holton, J. R.: Crosstropopause tracer transport in midlatitude convection, J. Geophys. Res., 110, doi:10.1029/2004JD005059, 2005.

Mullendore, G. L., Homann, A. J., Bevers, K., and Schumacher, C.: Radar reflectivity as a proxy for convective mass transport, J. Geophys. Res. D: Atmos., 114, D06113, doi:10.1029/2008JD011431, 2009.

Pickering, K. E., Dickerson, R. R., Huffman, G. J., Boatman, J. F., and Schanot, A.: Trace Gas Transport in the Vicinity of Frontal Convective Clouds, J. Geophys. Res., 93, 759-773, doi:10.1029/JD093iD01p00759, 1988.

Pickering, K. E., Thompson, A. M., Tao, W.-K., and Kucsera, T. L.: Upper Tropospheric Ozone Production Following Mesoscale Convection During STEP/EMEX, J. Geophys. Res., 98, 87378749, doi:10.1029/93JD00875, 1993.

Randall, D., Khairoutdinov, M., Arakawa, A., and Grabowski, W.: Breaking the Cloud Parameterization Deadlock, B. Am. Meteor. Soc., 84, 1547-1564, 2003.
Rotunno, R. and Klemp, J. B.: On the rotation and propagation of simulated supercell thunderstorms, J. Atmos. Sci., 42, 271-292, 1985 .

Takahashi, H. and Luo, Z.: Where is the level of neutral buoyancy for deep convection?, Geophys. Res. Lett., 39, L15809, doi:10.1029/2012GL052638, 2012.

Tessendorf, S. A., Miller, L. J., Wiens, K. C., and Rutledge, S. A.: The 29 June 2000 supercell observed during STEPS. Part I: Kinematics and microphysics, J. Atmos. Sci., 62, 4127-4150, = 2005.

Tessendorf, S. A., Rutledge, S. A., and Wiens, K. C.: Radar and lightning observations of normal and inverted polarity multicellular storms from STEPS, Mon. Weather Rev., 135, 3682-3706, 2007a.

Tessendorf, S. A., Wiens, K. C., and Rutledge, S. A.: Radar and lightning observations of the 3 June 2000 electrically inverted storm from STEPS, Mon. Weather Rev., 135, 3665-3681, $2007 \mathrm{~b}$.

Thompson, A. M., Tao, W.-K., Pickering, K. E., Scala, J. R., and Simpson, J.: Tropical Deep Convection and Ozone Formation, B. Am. Meteorol. Soc., 78, 1043-1054, doi:10.1175/15200477(1997)078<1043:TDCAOF>2.0.CO;2, 1997.

Thompson, R. L., Edwards, R., Hart, J. A., Elmore, K. L., and Markowski, P.: Close proximity soundings within supercell environments obtained from the Rapid Update Cycle, Weather Forecast., 18, 1243-1261, 2003.

UCAR: STEPS Operations Journal, available online at: http:// www.mmm.ucar.edu/pdas/STEPS/ops-journal.html, (last access: 27 June 2012), 2012a.

UCAR: DC3 Home Page, http://www.eol.ucar.edu/projects/dc3/ index.html, (last access: 1 July 2012), 2012b.

Wiens, K. C.: Kinematic, microphysical, and electrical structure and evolution of thunderstorms during the Severe Thunderstorm Electrification and Precipitation Study (STEPS), Ph.D. thesis, Colorado State University, USA, 2005. 